\title{
Namen- und Sachregister
}

Adorno, Theodor W.

Ausdruck (Husserl)

Bedeutung, Bedeutungskategorie (Husserl)

Begriffsschrift

bejahende Operationen

Bild

Bildtheorie (Tractatus)

Bühler, Karl

Caillois, Roger

Cassirer, Ernst

Curry, Huskell B.

Erleben der Bedeutung (Sehen von Aspekten)

Folgebeziehungen

Frege, Gottlob
$258 \mathrm{ff}$

379-380, 391-395

391-395

26ff

121-131

$75 \mathrm{ff}, 86-87,105,288 \mathrm{ff}$

60-61, 96-104, 167-168, 288ff, 293-295

85, 269ff, 281, 285

272, 278-279, 286

$13,87-88$

$101,119,125$

$332 \mathrm{ff}$

63, 94-95, 122, 125, 131

132-136, 146-147

17, 24-29, 48, 118-120,

124, 140ff, 168, 252,

263-269, 323

Gadamer, Hans-Georg

20, 82-86, 262ff, 280-282,

344-350

Gätschenberger, Richard

14-16, 157, 300-311, 316ff,

$376,390,398$

Gentzen, Gerhard

129,142

Grammatik eines Wortes (eines Begriffs)

313ff, 331-342

grammatische Sätze

325-330 
hermeneutische Charakteristik des Verstehens Hermes, Hans

344-350

Hertz, Paul

$141,321 \mathrm{ff}, 340 \mathrm{ff}$

Horizont des Interpreten der Sprache

138

346, 348ff, 363, 373,

431-542

Huizinga, Johan

$82,272-278,282 \mathrm{ff}$

Husserl, Edmund

16-17, 21, 120, 291, 296,

375-397, 400-401, 405-427

intentionaler Gegenstand (Husserl)

387-391

intentionales Erlebnis (Husserl)

381-387

Kagan, Moisej Samojlovitsch

83-84

Komplex

40ff, 51, 79-81

konstruktive Operationen

112-115

Lewis, Clarence Irving

142ff, 320ff

Logik von Fragen und Antworten

(Belnap, Steel)

350-364

logischer Raum

132ff, 145-147

Losev, Alexej Fjodorovitsch

$13,88-89,311$

Modell

256-261, 288-298

N-Operation

115-120, 235, 237

Operation, Operationen

13ff, 107-111, 340ff

Post, Emil

115,143

Proposition

30ff, $39 \mathrm{ff}$

propositionale Funktion

29ff, $42 \mathrm{ff}$

Rechtfertigung

45-47

Russell, Bertrand

17, 23-25, 29ff, 38ff, 50-52, 
52ff, 115ff, 123, 140-141, $160,162-163,270 \mathrm{ff}$

Schröter, Karl

$321 \mathrm{ff}$

Solipsismus

$165 \mathrm{ff}$

Sprachspiel

252-256, 282-288, 288-298,

311-319

Subjekt als Grenze der Welt

162-168

Symbol

8ff, 23ff, 50ff, 71-73,

87-89, 105, 149-169,

170-172, 299ff, 311-319

symbolische Operationen

319-325, 340ff

Symbolismus

$8 \mathrm{ff}, 12 \mathrm{ff}, 23 \mathrm{ff}, 52 \mathrm{ff}, 71-73$,

89-96, 136-139, 149-169,

170-172, 299ff, 322-323

Symbolsystem

299ff, 300-311

System

274ff, 284

Tarski, Alfred

$130,321 \mathrm{ff}$

Theorie mehrstelliger kognitiver Relationen

(Russell)

40ff, 52ff, 160, $162 \mathrm{ff}$

Theorie der Wahrheitsfunktionen (Tractatus) $61-65$

Theorie des Zeigens (Tractatus)

$65-70$

Typentheorie

$33 \mathrm{ff}, 49 \mathrm{ff}$

Ujomov, Avenir Ivanovitsch

$256,275 f f$

Verstehen eines Ausdrucks (Husserl)

395-398

Verstehen eines Satzes (eines Wortes)

149-157, 311ff, 331ff,

$364-373$

Verstehen und Meinen

$397-401$

Waismann, Friedrich

$133,260 \mathrm{ff}, 263,377 \mathrm{ff}$

Weiss, Paul

235

Whitehead, Alfred North

17, 24-25, 31ff, 42ff, 50-52, $116,123,140$ 